\title{
Biological Effects of Noble Gases
}

\author{
J. RŮŽIČKA, J. BENEŠ, L. BOLEK, V. MARKVARTOVÁ \\ Department of Biophysics, Medical Faculty of Charles University, Plzen̆, Czech Republic
}

Received May 23, 2007

Accepted May 29, 2007

On-line available May 31, 2007

\begin{abstract}
Summary
Noble gases are known for their inertness. They do not react chemically with any element at normal temperature and pressure. Through that, some of them are known to be biologically active by their sedative, hypnotic and analgesic properties. Common inhalation anesthetics are characterized by some disadvantages (toxicity, decreased cardiac output, etc). Inhalation of xenon introduces anesthesia and has none of the above disadvantages, hence xenon seems to be the anesthetic gas of the future (with just one disadvantage - its cost). It is known that argon has similar anesthetic properties (under hyperbaric conditions), which is much cheaper and easily accessible. The question is if this could be used in clinical practice, in anesthesia of patients who undergo treatment in the hyperbaric chamber. Xenon was found to be organ-protective. Recent animal experiments indicated that xenon decreases infarction size after ischemic attack on brain or heart. The goal of our study is to check if hyperbaric argon has properties similar to those of xenon.
\end{abstract}

\section{Key words}

Noble gases $\bullet$ Xenon• Argon $\bullet$ Diving $\bullet$ Anesthesia $\bullet$ Stroke

\section{Introduction}

Helium, neon, argon, krypton, xenon and radon are elements of the eighth group of the periodic table of elements. They are referred to as rare or noble gases. The notion of rare gases is not exact because the atmosphere alone contains one percent of argon and, comparing with other elements that occur in nature, they are not so rare. The term of noble gases is more precise as they are very inert due to the structure of their electron shell. Noble gases do not generate any chemicals under normal conditions. Only xenon can form fluorides but purely under the conditions of high temperature (at least $400{ }^{\circ} \mathrm{C}$ ), which is irrelevant for biological conditions (Shriver 1992).

Despite the perfect chemical indifference, noble gases are biologically active under certain conditions and it is the point of this work. Above all, available information and our own observation concerning xenon and argon will be gathered here.

Argon is the longest known and the least rare gas of the group of noble gases. Its presence in the atmosphere was already predicted by Cavendish in 1785 , when, after burning all the elements in the atmosphere, he had left $1 / 100$ of the original amount which was impossible to burn. Argon was discovered and described in 1894. It is used in industry as protective atmosphere for welding, in analytical chemistry for gas chromatography, and as thermal insulation. It is isolated in liquid distillation of air.

Xenon is a very rare gas and occurs in the earth's atmosphere at millionths of a percent. It is used (much diluted) in special flash lamps and lately as inhalation anesthetic in medicine, which will be mentioned further on. 
Nitrogen and noble gases under water

When one is under water, the most common respiratory medium is standard air. Nitrogen in air is at concentrations equalized in the whole body and is inert under the conditions of staying out of water. When one starts to dive the partial pressure of nitrogen in respired air increases and so does its amount in human body - and it stops being inert.

It is recognized by tunnel workers and divers that at a pressure above $400 \mathrm{kPa}$ symptoms of different human behavior occur. This influence of high pressure was reported for the first time in 1835: The functions of the brain are activated, imagination is lively, thoughts have a particular charm and in some persons symptoms of intoxication are present (Junod 1835). Different symptoms are associated. They are described by various authors as feeling of sleepiness. They are accompanied by hallucinations and impaired judgment, loss of memory, slowing of mental activity and performance and response to stimuli are delayed. Exposure to pressure higher than 1 MPa may result in loss of consciousness and air can be used as an anesthetic. There is a wide individual susceptibility. Whereas one diver is not narcotic at pressures of $600 \mathrm{kPa}$, another will be severely affected at $400 \mathrm{kPa}$ (Cousteau 1953).

The anesthetic properties due to breathing compressed air is not an isolated phenomena and noble gases are known for quite a long time by the same signs and symptoms but vary in their power (Carpenter 1953). The narcotic potency of noble gases was correlated in their different physical and chemical properties. The most satisfactory correlation is afforded by their lipid solubility (Table 1).

Table 1. Narcotic potency of different gasses (Bennet 2004).

\begin{tabular}{lccc}
\hline Gas & $\begin{array}{c}\text { Molecular } \\
\text { Weight }\end{array}$ & $\begin{array}{c}\text { Solubility } \\
\text { in lipid }\end{array}$ & $\begin{array}{c}\text { Relative } \\
\text { narcotic } \\
\text { potency }\end{array}$ \\
\hline $\mathrm{He}$ & 4 & 0.015 & 0.2 \\
$\mathrm{Ne}$ & 20 & 0.019 & 0.3 \\
$\mathrm{H}_{2}$ & 2 & 0.036 & 0.6 \\
$\mathrm{~N}_{2}$ & 28 & 0.067 & 1 \\
$\mathrm{Ar}$ & 40 & 0.14 & 2.3 \\
$\mathrm{Kr}$ & 84 & 0.43 & 2.5 \\
$\mathrm{Xe}$ & 131 & 1.17 & 25.6 \\
$\mathrm{O}_{2}$ & 32 & 0.11 & 1.7 \\
$\mathrm{CO}_{2}$ & 44 & 1.34 & 20.0 \\
\hline
\end{tabular}

The exact cause of inert gas narcosis is not known even today. The first (wrong) hypothesis was that the narcosis is the result of pressure per se (Junod 1835). This theory is falsified by the fact that the degree of narcosis is the function of composition of the breathing mixture and not only pressure. Thus, at $1 \mathrm{MPa}$ pressure compressed air is very narcotic whereas a mixture of 20 $\%$ oxygen and $80 \%$ helium is not. Another theory - the carbon dioxide theory - explains narcosis as a result of increased partial pressure of carbon dioxide in lungs. While increasing pressure, gas density grows and lung ventilation is compromised. It leads to increased tension of $\mathrm{CO}_{2}$ in the alveolus and subsequently in the organism. Experiments on animals showed increased $\mathrm{CO}_{2}$ by $10 \%$ (Bean 1950, Vail 1971) and metabolic results of these increases were considered to be the cause of narcosis.

However, it is in contradiction with the fact that the degree of narcosis is the function of the breathing mixture (see above). Other experiments with various breathing gases showed that a $\mathrm{CO}_{2}$ increase supports only narcosis development caused by these gases (Miles 1957).

The theory that is valid nowadays explains the function of aliphatic anesthetics, their affinity for lipids; it means their solubility in lipids. It was shown that spinal synapses are affected by inert gases and, moreover, the inhibitory mechanisms are affected before the excitatory ones and inert gases act on the anterior horn cell of the synapse (Somjen 1963). Inert gases showed a significant depression of auditory evoked potentials at the cortex and reticular formation (Bennet 1964, Hamilton 1986). Narcotic gas acts at different hydrophobic sites and narcosis occurs when a critical expansion is attained in some cell hydrophobic site (Abraini 1995).

Some changes in neurotransmitter concentration due to inert gas narcosis were found, such as decrease in dopamine and norepinephrine in the caudate and hypothalamus (Risso 1999). Nitric oxide may also be involved (Vojtosh 1999).

\section{Anesthetic and organ-protective influence of xenon}

Table 1 shows the high solubility in lipids, thanks to which this gas has an anesthetic effect already normobarically. As will be shown later, xenon has no doubt a number of advantages in comparison with commonly used inhalatory anesthetics.

Xenon has a higher binding energy with myoglobin compared with other noble gases and nitrogen. Therefore, it reaches stable values in tissue 
(Trudell 1998).

All of the anesthetics have a variously expressed negative inotropic effect, demonstrated in numerous clinical studies. The only exception is represented by xenon as it does not at all influence the function of the myocardium, it does not affect any ion channels in the myocyte (Huneke 2001). Compared to isoflurane it shows very rapid recovery from anesthesia. Due to such excellent qualities, xenon is used nowadays in clinical practice. The cost of xenon is thousands of euros for 1000 liters of gas, which impedes its massive use. Other effects of inhalation anesthetics by xenon can be summarized as follows: xenon increases the delta activity of cortex on EEG vs. anesthesia by propofol (Johnson 2003); it has a protective effect on brain perfusion auto regulation vs. anesthesia by halothane (Schmidt 2002); it increases perfusion of brain-stem, cortex, oblongata, cerebellum, it does not change perfusion of liver, kidneys, small intestine and colon, muscles, skin and heart (Schmidt 2001). It has lower symphatic and higher parasymphatic activity vs. total intravenous anesthesia (Hanss 2006).

As to the technical parameters of xenon anesthesia, we can state that it differs in its effects according to sex. The mean alveolar concentration MAC is $69.3 \%$ for men and $51.1 \%$ for women (Goto 2002). Xenon has a good analgesic effect; it suppresses catecholamine and hemodynamic reaction to surgery intervention (Marx 1997). Xenon shows similar interaction with mivacurium as propofol (Kunitz 2005).

Xenon can be used as sedative in minor doses. MAC for sedation is $27-45 \%$ and it is comparable with effects of propofol at $0.5 \mathrm{mg} \mathrm{kg}^{-1} \mathrm{~h}^{-1}$ (Bedi 2003). It decreases breathing frequency in sedative dose and it does not have any other side effects (vomiting, cough, laryngospasm).

The experiments show that besides anesthetic characteristics, xenon also has organ protective effect on heart and brain. The mechanism of this influence has not been sufficiently explained yet. According to a theory, brain damage after hypoxic/ischemic insult is caused by neuron apoptosis, which is influenced by the activation of $\mathrm{N}$-methyl-D-aspartate receptor. It was demonstrated that xenon blocks this receptor. Therefore, xenon seems to be used for example in neonatal asphyxia (David 2003).

After experimental occlusion of coronary artery performed in xenon anesthesia, quicker recovery of heart was demonstrated in comparison with total intravenous anesthesia (Hartlage 2004).

Experiments on rats and pigs showed reduction of brain and heart attack (Preckel 2006). A positive influence on the reduction of brain damage was demonstrated repeatedly by different authors. After the whole experimental brain hypoxia induced by carotid ligature with ensuing inhalation of hypoxic mixture, the subsequent xenon inhalation reduces morphologically obsrvable brain damage (Schmidt 2005). After local ischemia induced by cannulation of rat cerebral media, xenon improves both functional and histological results (Homi 2003).

It is suitable to complete the enumeration of the superlative features of xenon with pointing out its disadvantages. Xenon has a higher density than nitrogen or $\mathrm{N}_{2} \mathrm{O}$ and thus increases the relative airway resistance. Thereby it is possible that some groups of patients (e.g. COPD) can be endangered by the occurrence of intrinsic PEEP (Volta 1998).

Another theoretical disadvantage is the possibility of air bubble and microbubble enlargement caused by the lower solubility of xenon in plasma (similarly to $\mathrm{N}_{2} \mathrm{O}$, it diffuses into a balloon of endotracheal tube). However, this theory was not borne out in practice by means Doppler analysis (Lockwod 2006) and not even in vitro experiments: both $\mathrm{N}_{2} \mathrm{O}$ and xenon expand bubbles but $\mathrm{N}_{2} \mathrm{O}$ does it much more (Benavides 2006). Similar results were achieved in animal experiments (Grocott 2005).

In conclusion, it can be added that xenon has no impact on the environment, it is not a greenhouse gas, it does not smell and it is not harmful to the ozone layer.

The question arises whether such organ protective features can be found in other rare gases. It would be appropriate to choose a gas out of the whole group, which does not have normobaric anesthetic properties (which means it is not the most effective) but is closest of the remaining gases to these effects. Argon is such a gas. Hence, we will focus on this gas in the experimental part of our work.

\section{Methods}

The goal was to analyze the possibilities of experimental animals to stay in hyperbaric argon. A hyperbaric chamber with the capacity of 600 liters was used for this purpose. A plexiglas container connected by a tube with the outside environment was put in the chamber and it was connected to a mixing machine permitting to achieve different concentrations of oxygen and argon in the container. The proportion of these gases, 
which flushed the container in the course of the experiment, was set by means of ball flow meters. Gas concentration (or partial pressure of oxygen) was monitored by self-constructed oxymeter, calibrated for hyperbaric conditions. There was a heating in the container ensuring temperature range from 25 to $28^{\circ} \mathrm{C}$.

Ten laboratory rats, 15 weeks old, were put into the container and it was sealed. Anthropometric parameters of animals are shown in Table. 2. The course of the experiment is schematically illustrated in Fig. 1. Compression at the speed of $100 \mathrm{kPa}$ (10 meters of water column) per 5 min was initiated. From the pressure of $200 \mathrm{kPa}$ the pure argon with adjustable fraction of oxygen was inflated into the container to ensure the partial pressure of oxygen in the range of $40-60 \mathrm{kPa}$. Rats were carefully observed.

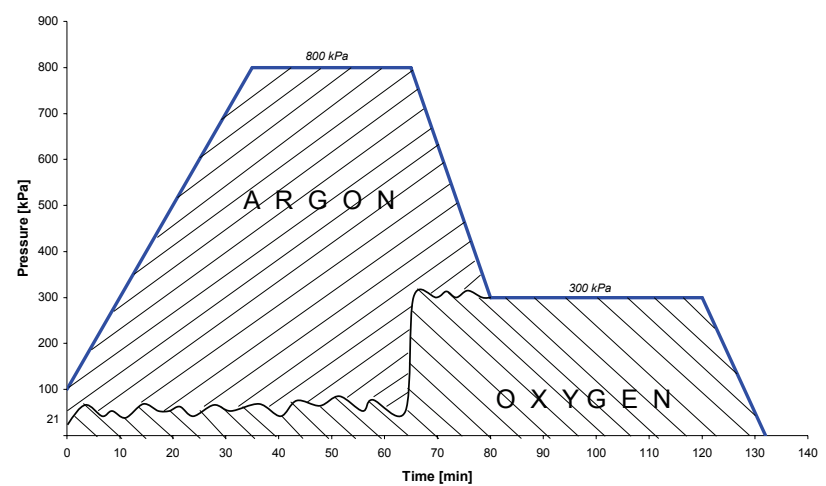

Fig. 1. Gas concentrations applied in the experiment.

The compression was stopped at maximum accessible pressure of $800 \mathrm{kPa}$. The oxygen concentration was maintained in the range $40-60 \mathrm{kPa}$ by changing oxygen and argon flow. After $30 \mathrm{~min}$ of this compression phase the decompression was started at a rate of $100 \mathrm{kPa}$ per $10 \mathrm{~min}$. At the same time, the flux of oxygen was increased to reach the partial pressure of $290 \mathrm{kPa}$ and then the oxygen was regulated to maintain this value see Fig. 1.

After pressure drop in the chamber to $300 \mathrm{kPa}$ decompression was stopped and the container was flushed only with pure oxygen for $40 \mathrm{~min}$. Then the chamber was decompressed fully. Animals were put back in the animal house and were observed in 8-hour intervals for the following 5 days.

The experiment was approved by the Ethic Committee of the Medical Faculty, Charles University at Plzeň.

\section{Results}

After putting the rats into the container and starting compression, the rats ran around the container behaving in a normal way. The first changes in their behavior took place when the pressure reached $500 \mathrm{kPa}$. The animals calmed down and showed minor motor activity. The state changed gradually to deterioration of motor coordination when some rats had problems rearing up; they fell over or had problems with coordinating limbs in motion. The first rat fell asleep (closed eyes and calm breathing were noticed) $10 \mathrm{~min}$ after the compression was finished. The times of argon hypnotic influence upon other rats are shown in Table 2. In the decompression stage, rats were gradually waking up and started behaving in a normal way. In further observations of rats according to the protocol (5 days) no divergence from the standard was noticed. The rats ingested and showed normal activity.

Table 2. Rat characteristics.

\begin{tabular}{lcccc}
\hline No & $\begin{array}{c}\text { Weight } \\
\text { [g] }\end{array}$ & Gender & $\begin{array}{c}\text { Falling } \\
\text { asleep time } \\
\text { [min] }\end{array}$ & $\begin{array}{c}\text { Waking } \\
\text { up time } \\
\text { [min] }\end{array}$ \\
\hline 1 & 300 & Male & 55 & 75 \\
2 & 290 & Male & 45 & 80 \\
3 & 320 & Male & 50 & 80 \\
4 & 290 & Male & 50 & 85 \\
5 & 310 & Male & 55 & 90 \\
6 & 300 & Female & 50 & 85 \\
7 & 300 & Male & No sleep & ------- \\
8 & 290 & Male & 60 & 90 \\
9 & 310 & Female & No sleep & -------- \\
10 & 300 & Male & 55 & 90 \\
\hline
\end{tabular}

\section{Discussion}

The object of our study was the potential organprotective effects of argon. Positive proofs about the effects of a gas from the same group, xenon, exist (see above), but its spread is impeded by its high price. But the use of the gas in excess pressure is joined with a possible serious, even mortal, effect - emergence of decompression disease. It is necessary to define empirically the protocol of ,hyperbaric argon therapy“ and verify its safety - and this is the subject of our work. 
Decompression tables for argon do not exist; regarding different (even double) solubility of argon from nitrogen, it is impossible to use standardized tables for nitrogen.

In the course of the experiment, we devoted ourselves to the observation of hypnotic influence of hyperbaric argon in the easiest possible way. The reaction to tactile or algic stimulation is not assessed, it is impossible to give the results of argon analgesic effects, which are obviously desirable for detailed examination of anesthesia. We are not adequately equipped for achieving such results. However, we do not consider it to be rational as the effects of noble gases including argon have already been described in literature and therefore it is not our focal point. Observation of animals after the end of the exposure means not developing any symptoms of decompression disease can be regarded as priority.

The pressure and concentration used correspond to the depth of $85 \mathrm{~m}$ water when breathing air, which is a plunge necessary to finish by decompression lasting for almost $7 \mathrm{~h}$ (according to Buhlman's algorithm) regarding the plunge profile (bottom time $30 \mathrm{~min}$ ). This is only rough time, reached by extrapolation as accessible algorithms exclude air breathing in such a depth because of oxygen toxicity and they automatically change the mixture to trimix - which means adding helium.
Moreover, argon is being breathed, not nitrogen and it has almost double solubility in lipids (Table 1). Therefore, we can only predict an even longer time of standard decompression with identical mixture. Such long decompression is not applicable from the point of view of planned use for therapeutic or repeated purposes; it is suitable only for single research purposes. That is why we used a modified record of decompression maximally using oxygen, which means setting partial pressure of oxygen to maximum possible value in terms of its side effects, i.e. $300 \mathrm{kPa}$. The value of decompression break on this maximum pressure of pure oxygen (40 min) was empirically determined as a period "a little longer" than the period of isocompression and, from the experimental result point of view, seems to be sufficient.

The submitted work can be characterized as a methodological preparation before an experiment studying the influence of hyperbaric argon therapy on ischemic brain damage. At present, the team of authors prepares a model of mice cerebral stroke; experiments will start after verifying an adequate model according to the record.

\section{Acknowledgements}

Supported by grant MSM 0021620819.

\section{References}

ABRAINI JH: Evidence for inert gas narcosis mechanisms in the occurrence of psychotic like episodes at pressure environment. Neuroreport 6: 2435-2439, 1995.

BEAN JW: Tensional changes of alveolar gas in reactions to rapid compression and decompression and question of nitrogen narcosis. Am J Physiol 161: 417-425, 1950.

BEDI A, MURRAY JM, DINGLEY J, STEVENSON MA, FEE JPH: Use of xenon as a sedative for patients receiving critical care. Crit Care Med 31: 2470-2477, 2003.

BENAVIDES R, MAZE M, FRANKS NP: Expansion of gas bubbles by nitrous oxide and xenon. Anesthesiology 104: 299-302, 2006.

BENNET PB, ROSTAIN JC: Inert gas narcosis. In: Physiology and Medicine of Diving. BRUBAKK AO, NEUMAN TS (eds), Saunders Elsevier Science, London 2004, 300-322.

BENNET PB: The effects of high pressures of inert gases on auditory evoked potentials in cat cortex and reticular formation. Electroenceph Clin Neurophysiol 17: 388-397, 1964.

CARPENTER FG: Depressant action of inert gases on the central nervous system in mice. Am J Physiol 172: 471-474, 1953.

COUSTEAU JY: The Silent World. Reprint Society, London, 1953.

DAVID HN, LEVEILLE F, CHAZALVIEL L, MACKENZIE ET, BUISSON A, LEMAIRE M, ABRAINI JH: Reduction of ischemic brain damage by nitrous oxide and xenon. J Cerebr Blood Flow 23: 1168-1173, 2003.

GOTO T, NAKATA Y, MORITA S: The minimum alveolar concentration of xenon in the elderly is sex dependent. Anesthesiology 97: 1129-1132, 2002.

GROCOTT HP, SATO Y, NOMI HM, SMITH BE: The influence of xenon, nitrous oxide and nitrogen on gas bubble expansion during cardiopulmonary bypass. Eur J Anaesthesiol 22: 353-358, 2005.

HAMILTON K, PORLIER G, LANDOLT J: Effects of inert gas narcosis on the vestibular ocular reflex. Undersea Biomed Res 13, 355-359, 1986. 
HANSS R, BEIN B, TUROWSKI P, CAVUS E, BAUER M, ANDRETZKE M, STEINFATH M, SCHOLZ J, TONNER PH: The influence of xenon on regulation of the autonomic nervous system in patients at high risk of perioperative cardiac complications. Br J Anaesth 96: 427-436, 2006.

HARTLAGE MAG, BERENDES E, VAN AKEN H, FOBKER M, THEISEN M, WABER TP: Xenon improves recovery form myocardial stunning in chronically instrumented dogs. Anesth Analg 99: 655-664, 2004.

HOMI HM, YOKOO N, MA DQ, WARNER DS, FRANKS NP, MAZE M, GROCOTT HP: The neuroprotective effect of xenon administration during transient middle cerebral artery occlusion in mice. Anesthesiology 99: 876-881, 2003.

HUNEKE R, JUNGLING E, SKASA M, ROSSAINT R, LUCKHOFF A: Effect of the anesthetic gases xenon, halothane, and isoflurane on calcium and potassium currents in human atrial cardiomyocytes. Anesthesiology 95: 999-1006, 2001.

JOHNSON BW, SLEIGH JW, KIRK IJ, WILLIAMS ML: High density EEG mapping during general anesthesia with xenon and propofol. Anaesth Iintensive Care 31: 155-163, 2003.

JUNOD T: Recherches sur les effets physiologiques et thérapeutiques de la compression et de rarefaction de l'air. Ann Gen Med 9: 157, 1835.

KUNITZ O, BAUMERT JH, HECKER Y, COBURN M, BEEKER T, ZUHLSDORFF A, FASSL J, ROSSAINT R: Xenon does not modify mivacurium induced meuromuscular block. Can J Anaesth 52: 940-943, 2005.

LOCKWOOD GG, FRANKS NP, DOWNIE NA, TAYLOR KM, MAZE M: Feasibility and safety of delivering xenon to patients undergoing coronary artery bypass. Anesthesiology 104: 458-465, 2006.

MARX T, WAGNER D, BAEDER S, GOERTZ A, GEORGIEFF M, GROEBA G: Hemodynamics and catecholamines in anesthesia with different concentrations of xenon. Appl Cardiopulm Pathophysiol 7: 215-221, 1998.

MILES S: The effect of changes in barometric pressures on maximum breathing capacity. Am J Physiol Lond, 137: 85$6 \mathrm{P}, 1957$.

PRECKEL B, WABER NC, SANDERS RD, MAZE M, SCHLACK W: Molecular mechanisms transducing the anesthetics, analgesic, and organ protective actions of xenon. Anesthesiology 105: 187-197, 2006.

RISSO JJ, SAGET A, TURLE N: Neurochemical and behavioral studies on narcosis. Undersea Hyperb Med 26, 81, 1999.

SCHMIDT M, MARX T, KOTZERKE J, LUDERWALD S, ARMBRUSTER S, TOPALIDIS R, SCHIRMER U, REINELT H: Cerebral and regional organ perfusion in pigs during xenon anesthesia. Anaesthesia 56: 1156$1159,2001$.

SCHMIDT M, MARX T, PAPP JAMBOR C, SCHRIMER U, REINELT H: Effect on cerebral autoregulation in pigs. Anaesthesia 57: 960-966, 2002.

SCHMIDT M, MARX, T, GLOGGL E, REINELT H, SCHRIMER U: Xenon attenuates cerebral damage after ischemia in pigs. Anesthesiology 102: 929-936, 2005.

SHRIVER DF, ATKINS PW, LANGFORD CH: The halogens and the noble gases. In: Inorganic Chemistry. Oxford University Press, 1992.

SOMJEN GG, GILL M: The mechanisms of the blockade of synaptic transmission in mammalian spinal cord by diethylether and thiopental. J Pharmacol Exp Ther 140: 19-30, 1963.

TRUDELL JR, KOBLIN DD, EDGER EI: A molecular description of how noble gases and nitrogen bind to a model site of anesthetic action. Anesth Analg 87: 411-418, 1998.

VAIL EG: Hyperbaric respiratory mechanics. Aerospace Med 42: 536-546, 1971.

VOJTOSH A, POPOV A, ALEKSEEVA OS: Role of nitric oxide in the mechanism on nitrogen narcosis. Undersea Hyperb Med 26: 81, 1999.

VOLTA CA, FERRARI A, ALVISI R, FERRARI E, RIGHINI ER, MARANGONI E, GRITTI G, GIUNTA F: Respiratory mechanics during xenon anesthesia - xenon as an external PEEP. Appl Cardiopulm Pathophysiol 7: 201-207, 1998.

\section{Corresponding author}

J. Růžička, Department of Biophysics, Faculty of Medicine, Charles University, Karlovarská 48, 30100 Plzeň, Czech Republic. E-mail: benes@dante.lfp.cuni.cz 